\title{
White Matter Injury after Repeated Endotoxin Exposure in the Preterm Ovine Fetus
}

\author{
JHODIE R. DUNCAN, MEGAN L. COCK, JEAN-PIERRE Y. SCHEERLINCK, \\ KERRYN T. WESTCOTT, CATRIONA MCLEAN, RICHARD HARDING, AND SANDRA M. REES \\ Department of Anatomy and Cell Biology [J.R.D., S.M.R.], Centre for Animal Biotechnology, School of \\ Veterinary Science [J.-P.Y.S.], University of Melbourne, Melbourne, Victoria, Australia; Department of \\ Physiology, Monash University, Melbourne, Victoria, Australia [M.L.C., K.T.W., R.H.]; Department of \\ Anatomical Pathology, Alfred Hospital, Melbourne, Victoria, Australia [C.M.]
}

\begin{tabular}{|c|c|}
\hline \multicolumn{2}{|c|}{ ABSTRACT } \\
\hline $\begin{array}{l}\text { Intrauterine infection has been linked to neurologic injury in } \\
\text { preterm infants. However, a reproducible model of white matter } \\
\text { injury in the preterm fetus in a long gestation species that can be } \\
\text { monitored in utero is currently unavailable. Thus, our objective } \\
\text { was to determine the effects of bacterial endotoxin (lipopolysac- } \\
\text { charide, LPS) on physiologic and inflammatory responses and } \\
\text { brain structure in the preterm ovine fetus. At } 0.7 \text { of gestation, six } \\
\text { catheterized fetuses received three to five intravenous injections } \\
\text { of LPS ( } 1 \mu \mathrm{g} / \mathrm{kg} \text { ) over } 5 \mathrm{~d} \text {; seven fetuses served as controls. Fetal } \\
\text { responses were monitored and brain tissue examined } 10-11 \text { d } \\
\text { after the initial LPS injection. After LPS on d } 1 \text { and } 2 \text {, fetuses } \\
\text { became transiently hypoxemic and hypotensive and blood IL-6 } \\
\text { levels were increased, but these responses were smaller or absent } \\
\text { after subsequent LPS exposures. Neural injury was observed in } \\
\text { all LPS-exposed fetuses, most prominently in the cerebral white } \\
\text { matter. Injury ranged from diffuse subcortical damage to periven- } \\
\text { tricular leukomalacia, and in the brainstem the cross-sectional } \\
\text { area of the corticospinal tract was reduced by } 30 \% \text { Thus, } \\
\text { repeated exposure of the preterm ovine fetus to LPS causes } \\
\text { neuropathology resembling that of cerebral palsy and provides a } \\
\text { robust model for exploring the etiology, prevention, and treat- } \\
\text { ment of white matter damage. (Pediatr Res } \mathbf{5 2 : ~ 9 4 1 - 9 4 9 , ~ 2 0 0 2 ) ~}\end{array}$ & $\begin{array}{l}\quad \text { Abbreviations } \\
\text { ABC, avidin-biotin-peroxidase } \\
\text { AMPA, alpha-amino-3-hydroxy-5-methyl-4-isoxazolepropionic } \\
\text { acid } \\
\text { bpm, beats per minute } \\
\mathbf{C a}^{2+} \text {, calcium } \\
\mathbf{C a O}_{2} \text {, arterial oxygen content } \\
\text { CNPase, 2',3'-cyclic nucleotide } 3 \text { '-phosphodiesterase } \\
\text { GA, gestational age } \\
\text { GFAP, glial fibrillary acidic protein } \\
\text { H\&E, hematoxylin and eosin } \\
\text { Hg, mercury } \\
\text { HR, heart rate } \\
\text { IR, immunoreactivity } \\
\text { LFB, Luxol fast blue } \\
\text { LPS, lipopolysaccharide } \\
\text { MAP, mean arterial pressure } \\
\text { MBP, myelin basic protein } \\
\text { NF, nuclear factor } \\
\text { Ov, ovine } \\
\text { Pao } \\
\text { PVL, partial pressure of arterial oxygen } \\
\text { SaO, arterial oxygen saturation } \\
\text { TNF, tumor necrosis factor }\end{array}$ \\
\hline
\end{tabular}

It has been hypothesized that infection during pregnancy, for example, bacterial vaginosis, urinary tract infection, or chorioamnionitis, can lead to preterm fetal brain injury (1-4). Furthermore, it has been hypothesized that such injury might result

Received December 7, 2001; accepted July 30, 2002.

Correspondence: Jhodie Duncan, Department of Anatomy and Cell Biology, University of Melbourne, Victoria, 3010, Australia; e-mail: J.Duncan@anatomy.unimelb.edu.au

Supported by the National Health and Medical Research Council of Australia, the Bonnie Babes Foundation, and the Australian Research Council.

R.H. and S.M.R. are joint senior authors.

DOI: 10.1203/01.PDR.0000034224.13885.BE from an inflammatory cascade initiated via mediators from the mother, placenta, or membranes (3). These hypotheses have been supported by clinical evidence that maternal infection is associated with both preterm birth and neonatal neurologic injury (5), and with increased levels of pro-inflammatory cytokines in amniotic fluid (6) and fetal blood (7). White matter damage is the most common form of brain injury and includes necrosis and cystic lesions in white matter adjacent to the lateral ventricles, usually referred to as PVL. The proinflammatory cytokines TNF- $\alpha$ (8) and IL-6 (9) have been identified within PVL (8) in human neonates. PVL is the main 
pathology associated with cerebral palsy in babies born between 24 and 32 wk of gestation (10-12).

To further investigate the mechanisms involved in preterm brain injury resulting from infection there is a need for appropriate animal models. LPS is a potent inflammatory agent and has been used to mimic infection because it initiates most components of an inflammatory response. Exposure to LPS in neonatal rats (13), kittens (1), and monkeys (13), as well as in fetal rats $(14,15)$ and rabbits $(16,17)$, leads to cerebral white matter damage, including PVL. However, in these studies, fetuses and neonates were not catheterized and hence physiologic data associated with brain injury would have been difficult to obtain; furthermore, cerebral injury was not observed in all animals exposed to LPS in these paradigms. The lack of reproducibility and catheterization in these models restricts their usefulness in developing strategies for prevention or amelioration of fetal brain injury. Thus, there is clearly a need to establish a reproducible model of white matter injury in the preterm catheterized fetus (18).

Our objective was to determine the effects of repeated administration of bacterial endotoxin (LPS) on physiologic and inflammatory responses and brain structure in the preterm ovine fetus. Sheep, like humans, have a long gestation $(\sim 147$ d), enabling brain development to be studied over prolonged periods; furthermore, catheterization enables pathophysiological and inflammatory responses to LPS to be characterized. In comparison with rodents, sheep have a greater volume of cerebral white matter due to extensive gyral formation; this is important when aiming to replicate major neuropathologies seen in human congenital brain disorders. In addition, the sheep is an appropriate species in which to study the developing immune response, as sheep and humans have reached a similar stage of immunologic development at birth, unlike rats and mice in which the peripheral lymphoid organs are poorly developed (19).

We administered repeated doses of LPS over $5 \mathrm{~d}$ to the ovine fetus in utero at 0.7 of gestation, which equates to $24-25 \mathrm{wk}$ in the human fetus, a period of high vulnerability to PVL (20, 21). Physiologic and inflammatory responses were monitored, and the fetal brain was examined $11 \mathrm{~d}$ after the initial LPS exposure.

\section{METHODS}

Surgical preparation. Aseptic surgery (22) was performed at $91.0 \pm 0.3 \mathrm{~d}$ after mating (term is $\sim 147 \mathrm{~d}$ ) on 11 pregnant ewes carrying single fetuses for implantation of catheters into a fetal femoral artery (for blood sampling) and vein (for LPS injection), and amniotic sac. Antibiotics [procaine penicillin $(200 \mathrm{mg} / \mathrm{mL})$ and dihydrostrepomycin (mycin $(250 \mathrm{mg} / \mathrm{mL})]$ were administered intramuscularly to the fetus. Postoperatively, sheep were held in individual pens with access to food and water. This study was approved by the relevant animal care committees.

Experimental protocol. We used repeated injections of LPS, as preliminary observations indicated that single injections of a sublethal dose were ineffective in causing overt brain damage. Beginning at $95 \mathrm{~d}$ of GA, six fetuses received a series of i.v. injections of LPS ( $1 \mu \mathrm{g} / \mathrm{kg}$ estimated fetal weight, Escherichia coli, 055:B55, Sigma Chemical, St. Louis, MO, U.S.A.) administered over 5 d (95-99 d GA). Four fetuses received five daily injections ( $5 \mu \mathrm{g}$ total) and two fetuses received three injections on alternate days ( $3 \mu \mathrm{g}$ total) owing to fetal arterial $\mathrm{SaO}_{2}$ not having returned to pre-exposure levels within $24 \mathrm{~h}$. Control fetuses received either five daily injections of saline over the same period $(n=5)$ or were not instrumented $(n=2)$. Before and for $8 \mathrm{~h}$ after LPS injections, fetal arterial blood samples were analyzed for $\mathrm{SaO}_{2}, \mathrm{CaO}_{2}, \mathrm{PaO}_{2}$, and $\mathrm{PaCO}_{2}$ (partial pressure of carbon dioxide, arterial), $\mathrm{pH}$ (pHa), hematocrit, and $\mathrm{Hb}$ (ABL 520, Radiometer, Copenhagen, Denmark), lactate and glucose concentrations (YSI 230 STAT; YSI Inc., Yellow Springs, OH, U.S.A.). Fetal MAP and HR were monitored (PowerLab, ADInstruments Pty. Ltd., Castle Hill, Australia).

Cytokine assay. Before and $6 \mathrm{~h}$ after each LPS injection, arterial blood and amniotic fluid samples were collected; samples were also collected at postmortem. Cytokine levels were analyzed against recombinant cytokines via standard capture ELISA techniques using ovine-specific MAb to proinflammatory cytokines; cytokines analyzed were ovine TNF- $\alpha$ $($ OvTNF- $\alpha$ ) (23), ovine IL-1 $\beta$ (OvIL-1 $\beta$ ) (24), and ovine IL-6 (OvIL-6) (25).

Preparation of the fetal brain. At $105.0 \pm 0.7 \mathrm{~d}$ GA, ewes and fetuses were humanely killed (sodium pentobarbital, 130 $\mathrm{mg} / \mathrm{kg}$ i.v.). The fetal brain was perfused with $4 \%$ paraformaldehyde in $0.1 \mathrm{M}$ phosphate buffer ( $\mathrm{pH}$ 7.4). Blocks of tissue (5-mm thick) were removed from both cerebral hemispheres, two from the frontal lobe at the level of the coronal and ansate sulci and two from the parietal and temporal lobes at the level of the Sylvian sulcus and optic chiasm. Blocks were also collected from the ventral hippocampus, mid-sagittal cerebellar vermis, brainstem (rostral medulla, area postrema), and cervical spinal cord (C3-5). The tissue was embedded in paraffin, serially sectioned $(8 \mu \mathrm{m})$, and stained with either $0.01 \%$ thionin, H\&E, LFB, Bielschowsky silver stain to identify degenerating axons and axonal spheroids, or acid fuchsin to identify dying cells (26). Sections containing brain injury were stained with Perls stain for hemosiderin. Frozen sections (40 $\mu \mathrm{m})$ were cut from blocks taken from the parietal and temporal lobes in three control fetuses for immunohistochemical identification of mature oligodendrocyte (MBP) and microglial markers (CD45) that are not reactive in paraffin-embedded tissue.

Immunohistochemistry. Three sets of consecutive paraffin sections of the cerebral hemispheres (at the level of the ansate sulcus) in three control fetuses were reacted with antibodies for the following markers of the oligodendrocyte lineage: rabbitanti-rat chondroitin sulfate proteoglycan NG-2 (NG-2) (1:200, Chemicon International, Temecula, CA, U.S.A.), mouse-antiglycolipid O4 (1:10, Roche Molecular Biochemicals, Mannheim, Germany), and mouse-anti-human 2',3'-cyclic nucleotide 3'-phosphodiesterase (CNPase) (1:100, Sigma Chemical) to identify progenitor oligodendrocytes, preoligodendrocytes, and immature/mature oligodendrocytes, respectively (27-29). In all fetuses, sections of the spinal cord and hemispheres were reacted for CNPase and counterstained with acid fuchsin to 
identify cells of the oligodendrocyte lineage that were dying; other sections were reacted with rabbit-anti-cow glial fibrillary acidic protein (GFAP) antibody (1:500, DAKO, Glostrup, Denmark) to identify reactive astrocytes. Free-floating frozen sections of cerebral hemispheres were reacted with mouse-antimonkey MBP (1:500, Roche Molecular Biochemicals) to identify mature myelin and mouse-anti-CD45 (30) to identify bone marrow-derived phagocytic cells, particularly microglia and macrophages. All sections were incubated in the appropriate secondary antibodies and reacted using the $\mathrm{ABC}$ complex (Vector Laboratories, Burlingame, CA, U.S.A.) (31). NG-2-, O4-, and CNPase-stained sections were pretreated with $0.02 \%$ proteinase $\mathrm{K}\left(30 \mathrm{~min}\right.$ at $37^{\circ} \mathrm{C}$ ) before incubation with primary antibody. In immunohistochemical and histochemical procedures, tissues were stained simultaneously to reduce variability. When the primary antibody was omitted, staining failed to occur.

Histochemistry. Paraffin sections from all regions were stained with Griffonia (Bandeiraea) simplicifolia $\mathrm{B}_{4}$-isolectin (1:50, Vector Laboratories) and reacted with the ABC complex to identify activated microglia and infiltrating peripheral macrophages.

Qualitative analysis. From each fetus, a minimum of four sections with each stain (thionin, H\&E, LFB, Bielschowsky, acid fuchsin and Perls) were examined independently by three trained observers (JRD, SMR, CM) to identify structural changes including lesions/cysts, axonal degeneration, glial cell aggregations, the presence of leukocytes, cell death, hemosiderin-positive cells, and regions of pallor in the neuropil. White matter injury was then classified as PVL or diffuse damage according to the following criteria: PVL consisted of focal patches of necrosis (or cystic necrosis) and gliosis in the white matter adjacent to the lateral ventricles; diffuse white matter injury consisted of areas of gliosis with associated axonal injury in the subcortical white matter.

Quantitative morphometric analysis. For each fetus, the analyses described below were performed on four to six sections from each brain region sampled and a mean value for each fetus determined:

1. Sections were projected onto a digitizing tablet and the cross-sectional areas of the total white matter, PVL, and diffuse injury determined (Sigma Scan Pro Plus v4.0, SPSS Science, Chicago, IL, U.S.A.).

2. The severity of PVL, gliosis, and axonal degeneration was assessed using the following scoring system: $0=$ no alterations, $+=$ minimal, $++=$ mild, $+++=$ extensive, $++++=$ extreme damage.

3. Throughout the cerebral hemispheres (gray matter, white matter, or striatum), brainstem, and spinal cord, the proportion of neuropil occupied by blood vessels was estimated by point counting (32) in thionin-stained sections to determine whether there were any long term effects on the vasculature.

4. In serial sections of the cerebral hemisphere, cell profiles that contained a nucleus and were positive for $\mathrm{NG}-2, \mathrm{O} 4$, or CNPase in the white matter (superficial, mid-, and deep) were counted in five fields per animal. The results are presented as proportions of each cell type in the tissue examined.
5. The cross-sectional area of the corticospinal tract was measured at the level of the obex.

6. In acid fuchsin-stained sections of brainstem and spinal cord, stained cells were counted in the total cross-sectional area and expressed as cells per millimeter squared.

7. The density (cells per millimeter squared) of Purkinje cells was determined in the cerebellum.

Regression analysis. Regression analyses were performed in LPS-exposed fetuses between the total percentage of cerebral white matter injury and a range of fetal responses to LPS, namely, maximal changes in fetal $\mathrm{CaO}_{2}, \mathrm{MAP}, \mathrm{pHa}$, and plasma IL-6 concentrations (at $6 \mathrm{~h}$ after the first exposure). The physiologic responses used in this analysis were those on the first day of LPS exposure, and were expressed as a percentage of control (pre-LPS) values.

Statistical analysis. All measurements (qualitative and quantitative) were performed on coded slides or samples. Differences between LPS-exposed and control fetuses were analyzed by a two-way repeated ANOVA (physiologic data) or the Mann-Whitney $U$ test (cytokine levels and histologic data). Differences were considered significant at $p<0.05$. Data are presented as mean \pm SEM (physiologic data) or a mean of means \pm SEM (cytokine levels and histologic data).

\section{RESULTS}

\section{Fetal Blood Composition}

Repeated LPS administration resulted in both acute and chronic physiologic responses over the 5-d treatment period; these effects are described separately.

Acute responses. From 3-7 h after the first exposure to LPS, fetuses became hypoxemic and acidemic with $\mathrm{PaO}_{2}, \mathrm{CaO}_{2}$, and $\mathrm{pHa}$ falling by $4.0 \pm 0.8 \mathrm{~mm} \mathrm{Hg}, 1.3 \pm 0.1 \mathrm{mmol} / \mathrm{L}$, and 0.05 \pm 0.01 , respectively $(p<0.05)$ (Fig. 1$)$. These acute responses to LPS were attenuated following subsequent exposures, with a significant reduction in $\mathrm{PaO}_{2}(-3.7 \pm 0.8 \mathrm{~mm} \mathrm{Hg})$ but not $\mathrm{CaO}_{2}(-0.9 \pm 0.2 \mathrm{mmol} / \mathrm{L})$ and $\mathrm{pHa}(-0.03 \pm 0.1)$ on $\mathrm{d} 3$, and no significant changes in any of the three variables after LPS on d 4 and 5. Fetal lactate concentrations were elevated 3-7 h after each LPS exposure (Fig. 1). The lactate response was greatest on $\mathrm{d} 1$, with concentrations rising from $0.7 \pm 0.1$ $\mathrm{mmol} / \mathrm{L}$ pre-LPS to $1.7 \pm 0.3 \mathrm{mmol} / \mathrm{L}$ post-LPS. There were small, transient increases in fetal $\mathrm{PaCO}_{2}$, hematocrit, $\mathrm{Hb}$, and glucose concentrations after the initial exposure to LPS, but these were not significant.

Chronic responses. In control fetuses, baseline $\mathrm{PaO}_{2}(21.2 \pm$ $0.9 \mathrm{~mm} \mathrm{Hg})$ and $\mathrm{CaO}_{2}(3.5 \pm 0.1 \mathrm{mmol} / \mathrm{L})$ were not altered over the 5-d treatment period. In contrast, LPS-exposed fetuses became mildly hypoxemic over the 5 -d period, with baseline $\mathrm{PaO}_{2}(16.9 \pm 0.9 \mathrm{~mm} \mathrm{Hg})$ and $\mathrm{CaO}_{2}(2.7 \pm 0.3 \mathrm{mmol} / \mathrm{L})$ falling to values significantly below those in control fetuses by $23 \mathrm{~h}$ after LPS administration on d 5. Baseline fetal pHa (LPS, 7.37 \pm 0.01 versus control, $7.37 \pm 0.01), \mathrm{PaCO}_{2}$ (LPS, $46.7 \pm 1.1$ versus control, $44.1 \pm 0.3 \mathrm{~mm} \mathrm{Hg}$ ), hematocrit (LPS, $29 \pm 2$ versus control, $27 \pm 1 \%$ ), lactate (LPS, $0.7 \pm 0.1$ versus control, $0.8 \pm 0.1 \mathrm{mmol} / \mathrm{L}$ ) and glucose (LPS, $1.0 \pm 0.1$ versus control, $0.9 \pm 0.1 \mathrm{mmol} / \mathrm{L})$ concentrations were not significantly different between LPS-exposed and control fetuses over 

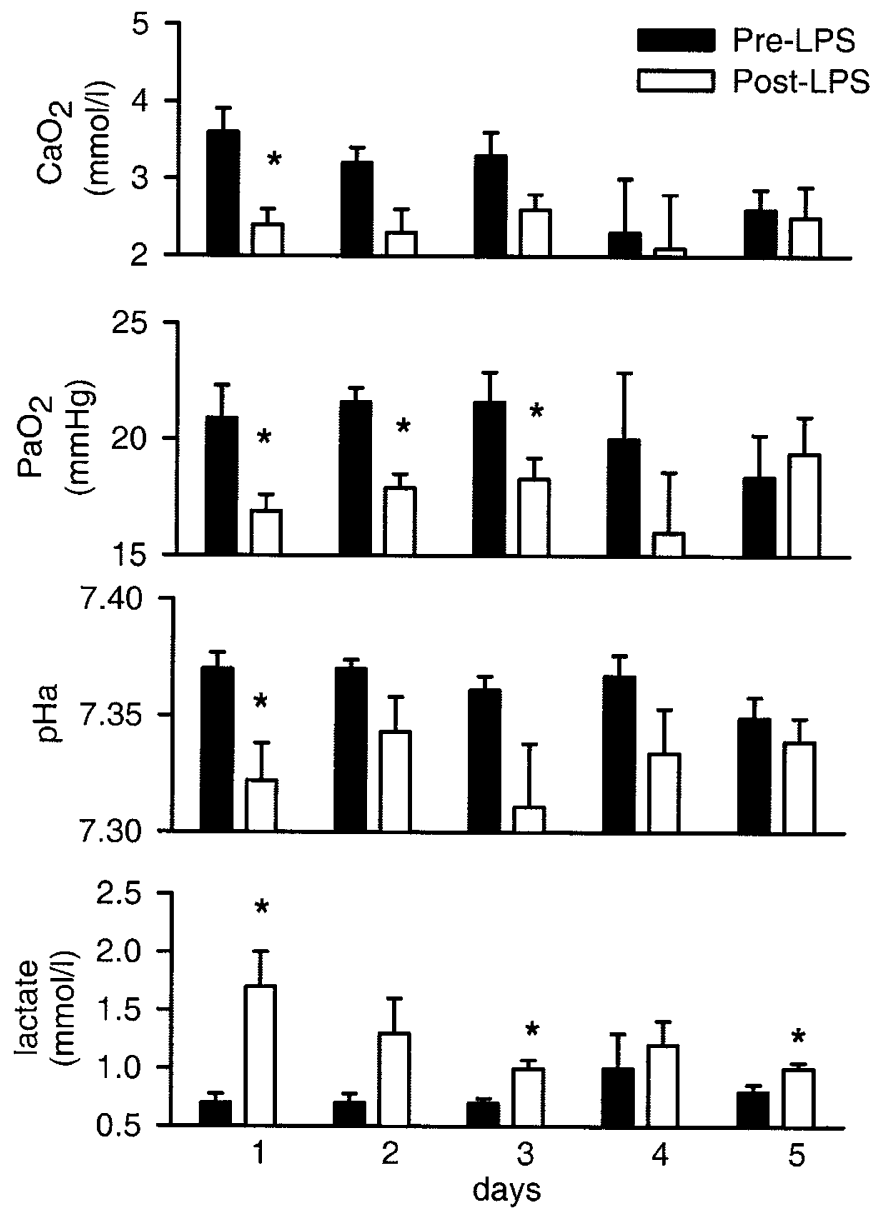

Figure 1. Acute physiologic responses to LPS. Fetal arterial oxygen content $\left(\mathrm{CaO}_{2}, \mathrm{mmol} / \mathrm{L}\right)$, oxygen tension $\left(\mathrm{PaO}_{2}, \mathrm{~mm} \mathrm{Hg}\right), \mathrm{pHa}$, and blood lactate concentrations $(\mathrm{mmol} / \mathrm{L})$ in LPS-exposed fetuses after repeated LPS exposures. Mean values \pm SEM before (solid bar) and maximal changes at 3-7 h after (open bar) the LPS exposure are shown. Fetuses became hypoxemic with elevated lactate concentration and a mild acidemia after the initial LPS exposure; these responses attenuated with each successive LPS exposure. Asterisks $(*)$ indicate differences $(p<0.05)$ between each pre and post LPS exposure.

the 5-d treatment period; the exception was a small but significant fall in $\mathrm{pHa}(7.34 \pm 0.01)$ at the end of $\mathrm{d} 5$. All variables had returned to control values by $48 \mathrm{~h}$ after the final exposure to LPS.

\section{Fetal Mean Arterial Pressure and Heart Rate}

Acute responses. The initial exposure to LPS caused fetuses to become hypotensive, with MAP falling from $27.8 \pm 0.9$ to $23.0 \pm 1.4 \mathrm{~mm} \mathrm{Hg}(p<0.05)$ at $5 \mathrm{~h}$ after LPS administration. This acute response to LPS was attenuated on subsequent days, with a tendency for MAP to be reduced on the second day $(27.3 \pm 1.8$ versus $23.9 \pm 1.3 \mathrm{~mm} \mathrm{Hg})$ and no significant response on subsequent days. Fetal HR was not significantly altered after endotoxin exposure.

Chronic responses. In control fetuses, MAP $(31.4 \pm 1.0 \mathrm{~mm}$ $\mathrm{Hg}$ ) and $\mathrm{HR}(196 \pm 5 \mathrm{bpm})$ were not significantly altered over the 5-d treatment period; LPS exposure had no effect on baseline MAP $(27.8 \pm 1.0 \mathrm{~mm} \mathrm{Hg})$ and $\mathrm{HR}(188 \pm 9 \mathrm{bpm})$.

\section{Cytokine Analysis}

After the first exposure to LPS, plasma concentrations of IL-6 were increased at $6 \mathrm{~h}(14.5$-fold, $p<0.02)$ and $23 \mathrm{~h}$ (1.5-fold, $p<0.04)$ (Fig. 2). The response was attenuated on d 2, with IL-6 elevated at $6 \mathrm{~h}$ after the second exposure (4.6-fold, $p<0.03$ ) but not at $23 \mathrm{~h}$. No changes occurred on subsequent days. IL-6 was undetectable in amniotic fluid over the entire experimental period. There were no alterations in TNF- $\alpha$ or IL- $1 \beta$ concentrations in plasma or amniotic fluid at 6 or $23 \mathrm{~h}$.

\section{Brain and Body Weights}

At postmortem $(105.0 \pm 0.7 \mathrm{~d})$, there were no significant differences in brain weights of LPS-exposed and control fetuses (LPS, $24.1 \pm 1.1$ versus control, $24.4 \pm 0.1 \mathrm{~g}$ ). Similarly, fetal body weights were not different (LPS, $1.1 \pm 0.1$ versus control, $1.2 \pm 0.1 \mathrm{~kg})$.

\section{Structural Analysis of the Brain}

Cerebral hemispheres: white matter. Cerebral white matter injury ranged from diffuse damage observed in all LPSexposed fetuses to PVL in two of the fetuses; this damage occupied $1-8.5 \%$ of the total cerebral white matter in the regions examined (Table 1). In one LPS-exposed fetus (a fetus with PVL), damage was observed in all frontal, parietal, and temporal brain sections examined. In three of the LPS-exposed fetuses, damage was observed in all parietal and temporal sections and in $50 \%$ of frontal sections and in two others damage was observed only in either the frontal or parietal

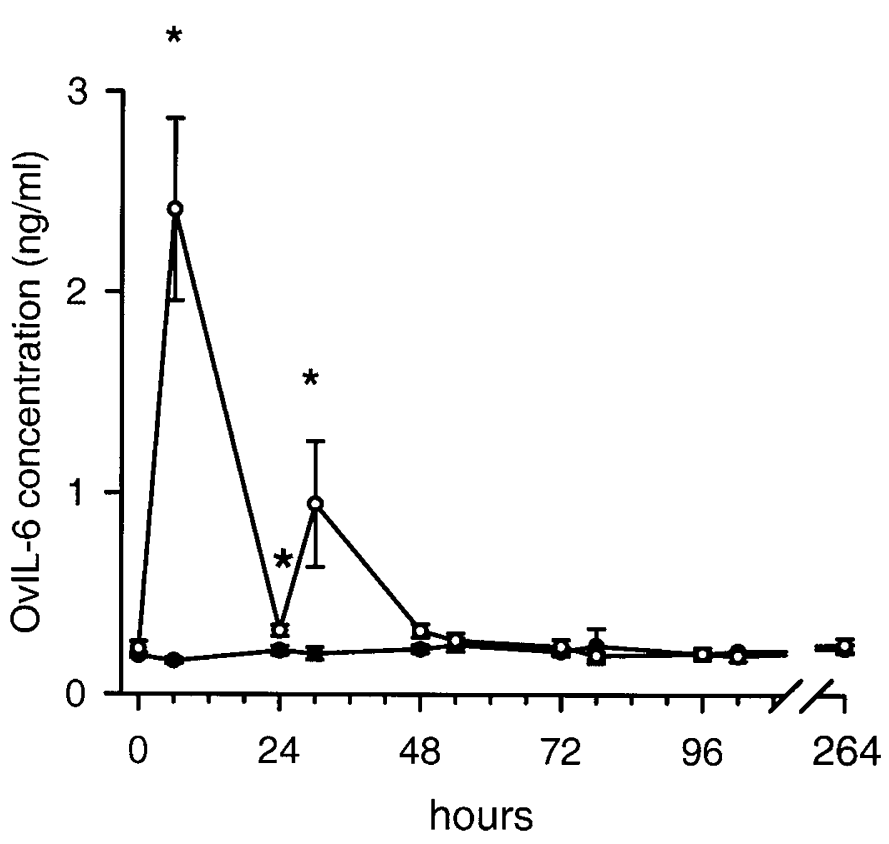

Figure 2. IL-6 responses to LPS. Concentrations of fetal plasma OvIL-6 in LPS-exposed (open circle) and control (filled circle) fetuses over the $5 \mathrm{~d}$ of LPS injections. Points represent mean values \pm SEM. Note the significant increases at 6 and $23 \mathrm{~h}$ after the first LPS injection (delivered at $0 \mathrm{~h}$ ) and $6 \mathrm{~h}$ after the second LPS injection (delivered at $24 \mathrm{~h}$ ). Asterisks (*) indicate differences $(p<0.05)$ compared with controls. 
Table 1. Cerebral white matter injury in individual LPS-exposed fetuses

\begin{tabular}{|c|c|c|c|c|c|c|}
\hline \multirow[b]{2}{*}{ Fetus } & \multirow[b]{2}{*}{$\begin{array}{l}\text { No. of exposures to } \\
\text { LPS }(1 \mu \mathrm{g} / \mathrm{kg})\end{array}$} & \multicolumn{2}{|c|}{ Extent of injury } & \multicolumn{3}{|c|}{ Severity of injury } \\
\hline & & $\%$ White matter occupied by PVL & $\begin{array}{c}\% \text { White matter occupied by diffuse } \\
\text { injury }\end{array}$ & PVL & Gliosis & Axonal degeneration \\
\hline LPS \#2 & 3 & 0 & $3.6 \pm 1.0$ & 0 & ++ & ++ \\
\hline LPS \#6 & 5 & 0 & $3.5 \pm 1.7$ & 0 & +++ & +++ \\
\hline LPS \#1 & 3 & $1.0 \pm 0.3$ & $1.5 \pm 0.8$ & +++ & +++ & +++ \\
\hline
\end{tabular}

Values are means \pm SEM for individual LPS-exposed fetuses. 0 , no alterations; + , minimal; ++ , mild; +++ , extensive; ++++ , extreme.

LPS fetuses ranked from greatest to least percentage of white matter injury.

sections. There was no evidence that damage occurred preferentially in the right or left hemisphere. No differences were observed in the extent of the injury in fetuses that received three doses versus five doses of LPS; PVL occurred in one fetus from each protocol (Table 1).

In the two fetuses with PVL, multifocal necrotic lesions $(\sim 2$ $\mathrm{mm}$ in diameter) were present in the periventricular white matter adjacent to the dorsal aspect of the lateral ventricle. In fetus \#1 (Table 1) it occupied 1.0\% of the total cerebral white matter but in fetus \#4 it occupied $6.4 \%$. In the latter case, white matter necrosis extended into the corpus callosum, subcortical white matter, anterior limb of the internal capsule, and the external capsule. These lesions were observed as a white opacity in unstained tissue (Fig. $3 B$ LPS versus Fig. $3 A$ control). In thionin-stained sections (Fig. $3 D$ LPS versus Fig. $3 C$ control), gliosis was observed surrounding the necrotic lesions and in extensive patches throughout the periventricular white matter. Bielschowsky stain revealed many axonal spheroids resulting from the focal disruption of axons within the infarct (Fig. 3, $E$ and $F$; Table 1). Within the regions of damage, we also observed reactive endothelium, leukocytes, primarily agranulocytes but occasionally neutrophils, and erythrocytes. We observed no evidence of intraventricular hemorrhage.

In control fetuses, ramified microglia were sparsely distributed throughout the cortex, subcortical white matter, and striatum as revealed by CD45-IR (not shown). Lectin histochemistry in LPS-exposed fetuses revealed stained cells around the walls of the lateral ventricles, in the corpus callosum, and in degenerating tissue around blood vessels adjacent to the most caudal extent of the posterior horn of the lateral ventricles in the temporal lobe. Numerous stained cells were present within and surrounding the regions of PVL (Fig. $3 G$ ). Cells within the core of the lesion were rounded and vacuolated suggesting active phagocytosis; these could have been infiltrating peripheral macrophages or activated microglia, but we cannot presently distinguish between these cell types. Cells on the periphery of the cyst had the morphology of microglia, ranging from a resting (ramified) to an active (amoeboid) state (Fig. 3H). Within these regions there was marked perivascular cuffing (Fig. 3H). Cells at injury sites did not stain positively for hemosiderin, suggesting that there was no recent phagocytosis of erythrocytes. GFAP-IR cells and processes were also present within the areas of PVL (not shown).

Diffuse areas of damage were located in the subcortical cerebral white matter, most consistently at the gyral crests (Fig.
$3 J$ LPS versus Fig. 3I control). The damage consisted of gliosis, predominantly lectin-positive cells with similar morphologies to those described in PVL lesions, GFAP-positive astrocytes, some axonal spheroids, a generally pallid underlying neuropil, infiltrating leukocytes, and reactive endothelium. The percentage of total white matter occupied by injury ranged from $1 \%$ (fetus \#5) to $3.6 \%$ (fetus \#2) (Table 1). At sites of both PVL and diffuse injury, acid fuchsin-positive cells were present and $\sim 80 \%$ of these cells were found to be CNPase positive, indicating that they were differentiated oligodendrocytes.

Characterization of oligodendrocyte development at $105 d$ gestation. In control fetal brain tissue at $105 \mathrm{~d}$ of gestation, NG-2-, O4-, and CNPase-positive cells were present in the superficial, mid-, and deep cerebral white matter (Fig. 4A-C) and were present in the proportions of 1 (NG-2):4 (O4):2 (CNPase). As described in the human (20,21), NG-2-positive cells were bipolar with elongated cell bodies and long processes, O4-positive cells had rounder cell bodies and more branched processes, and CNPase-positive cells had rounded cell bodies and extensive processes that were strongly immunoreactive. The populations of cells staining with NG-2, O4, or CNPase differed in morphology and distribution from those stained with GFAP (astrocytes) and CD45/lectin (microglia, macrophages). MBP-IR was detected in all brains, although the staining was not as intense as for CNPase-IR; it was more pronounced in the striatal white matter than in the subcortical white matter, suggesting myelination was more advanced in the striatum.

Cerebral hemispheres: striatum and gray matter. In LPSexposed fetuses there were no infarcts, cell death, aggregations of activated glial cells, infiltrating leukocytes, or areas of tissue pallor in the striatum or gray matter, even in the regions adjacent to white matter damage.

There were no unusual features in the cerebral hemispheres of the seven control fetuses apart from a small region of lectin-positive cells in the gyral crest white matter in three of them. This staining was confined to one region in the parasagittal gyrus in each of the three affected fetuses (one catheterized, two noncatheterized) and was less intense than in LPSexposed fetuses.

Hippocampus and cerebellum. There was no evidence of white matter damage, dying cells, or reactive glia in the hippocampus or cerebellum. Furthermore, in the cerebellum there was no difference in the density of Purkinje cells between 

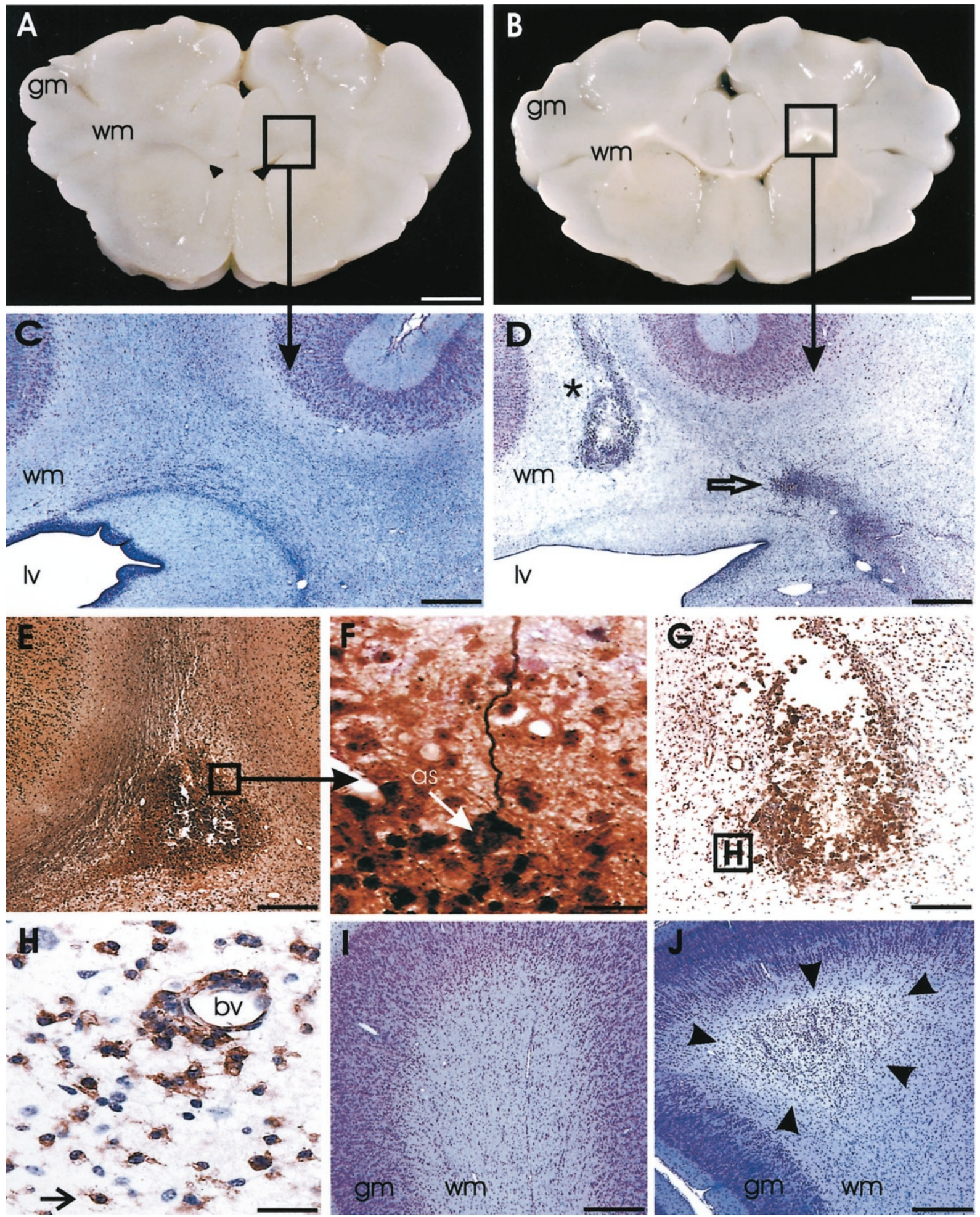

Figure 3. Cerebral white matter injury. Photomicrographs of transverse sections from the cerebral hemispheres in control $(A, C, I)$ and LPS-exposed ( $B, D, E-H$, $J)$ fetuses at $105 \mathrm{~d}$ of gestation. Damage in the periventricular region extending into the corpus callosum, subcortical white matter, and internal and external capsule was identified by its white, opaque appearance in unstained sections in LPS-exposed fetuses $(B)$, which was absent in controls $(A)$. In thionin-stained sections of LPS-exposed fetuses $(D)$ compared with controls $(C)$, cystic lesions $\left(^{*}\right)$ and regions of degenerating white matter infiltrated with glia (open arrow) were observed. $(E)$ Axonal degeneration in a necrotic, focal lesion (Bielschowsky silver stain); at higher magnification $(F)$ axonal spheroids $(a s)$ were observed. In regions of necrotic white matter damage $(G)$, aggregates of lectin-positive cells (stained brown) were present. $(H)$ Enlargement of section labeled $\mathrm{H}$ in $(\mathrm{G})$. Cells on the outer rim of the lesion had cytoplasmic processes (arrow) typical of microglia changing from a ramified (resting) to amoeboid (active) state. Within the area of damage there was marked perivascular cuffing. In LPS-exposed fetuses $(J)$ compared with controls $(I)$, diffuse damage was observed in the subcortical white matter and consisted of cellular infiltration and regions of pallor within the neuropil (arrowheads). $b v$, blood vessels; gm, gray matter; $l v$, lateral ventricle; $w m$, white matter. Scale bars: $A, B: 4.60 \mathrm{~mm} ; C, D: 528 \mu \mathrm{m} ; E-I, J: 440 \mu \mathrm{m} ; F: 20 \mu \mathrm{m} ; G: 215 \mu \mathrm{m} ; H: 36 \mu \mathrm{m}$. 


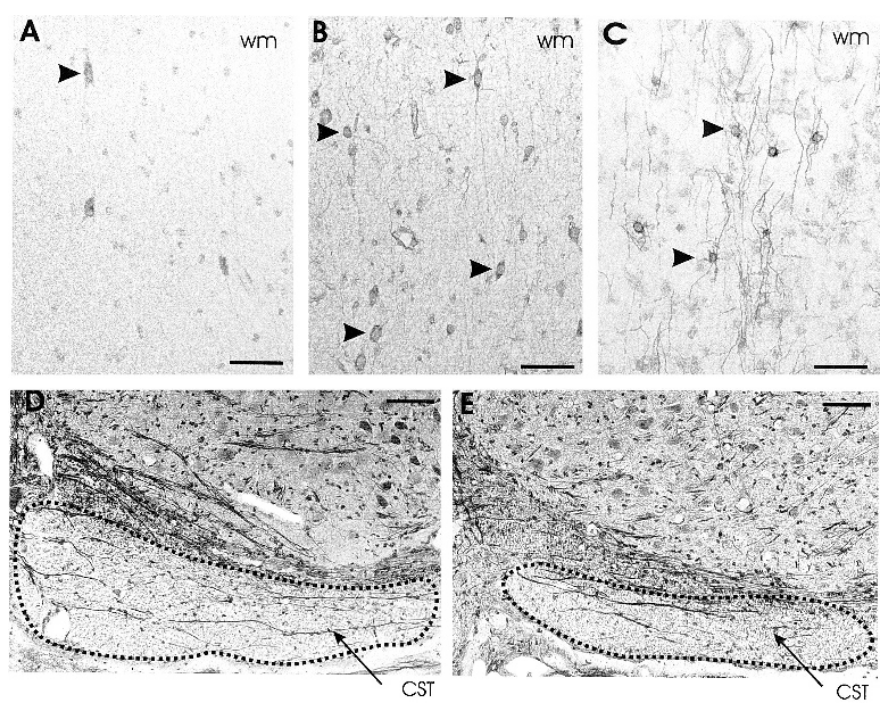

Figure 4. Oligodendrocyte lineage and neuropathology of the medullary corticospinal tract. Photomicrographs from control tissue of the subcortical white matter (105 d of gestation) showing $(A)$ NG-2-positive progenitor cells (arrow); (B) O4-positive preoligodendrocytes (arrows); and (C) CNPasepositive oligodendrocytes (arrows). Photomicrographs of transverse sections of the medullary corticospinal tract and surrounding tissue stained with Bielschowsky silver stain ( $D$ : control; $E$ : LPS). Note the significant reduction in the cross-sectional area of the corticospinal tract (dotted outline) in LPSexposed fetuses $(E)$. CST, corticospinal tract. Scale bars: $A-C$ : $39 \mu \mathrm{m} ; D, E$ : $140 \mu \mathrm{m}$.

LPS-exposed and control fetuses (LPS, $723 \pm 40$ versus control, $704 \pm 30$ cells $/ \mathrm{mm}^{2}$ ).

Brainstem. No lesions were observed in the brainstems of LPS-exposed or control fetuses. The cross-sectional area of the corticospinal tract in LPS-exposed fetuses was, on average, $30 \%$ smaller than in controls (LPS, $0.14 \pm 0.02$ versus control, $0.20 \pm 0.02 \mathrm{~mm}^{2}, p<0.03$ ) (Fig. $4 E$ LPS versus Fig. $4 D$ control). There was no evidence of degenerating fibers within the corticospinal tract nor in any other region of the white matter. There were no differences in the number of acid fuchsin-positive cells in the brainstem (LPS, $1.74 \pm 0.16$ versus control, $1.48 \pm 0.23$ cells $/ \mathrm{mm}^{2}$ ). In LPS-exposed fetuses, aggregations of leukocytes (primarily lymphocytes) were apparent within blood vessels and the perivascular tissue of the area postrema, but reactive glia were not observed.

Spinal cord. In LPS-exposed fetuses no overt changes were observed in the morphology of neurons or in the white matter in the cervical spinal cord, nor was there any evidence of gliosis. There were more acid fuchsin-positive cells within the white matter (LPS, $4.84 \pm 0.36$ versus control, $3.91 \pm 0.23$ cells $/ \mathrm{mm}^{2}, p<0.05$ ) but not the gray matter (LPS, $2.20 \pm 0.48$ versus control, $1.24 \pm 0.14$ cells $/ \mathrm{mm}^{2}$ ) of LPS-exposed fetuses compared with controls. CNPase was co-localized in about $50 \%$ of the acid fuchsin-positive cells.

Blood vessels. Quantitative analysis revealed no difference between LPS-exposed fetuses and controls in the percent of neuropil occupied by blood vessels in the cerebral gray matter, white matter, striatum, brainstem, and spinal cord.

Regression analysis. Within the LPS-exposed fetuses, there was no significant correlation between the percentage area of white matter injured and fetal responses to LPS, namely changes in $\mathrm{CaO}_{2}\left(R^{2}=0.10, p=0.54\right), \operatorname{MAP}\left(R^{2}=0.006, p\right.$ $=0.90), \mathrm{pHa}\left(R^{2}=0.08, p=0.58\right)$, and IL-6 $\left(R^{2}=0.30, p=\right.$ $0.34)$.

\section{DISCUSSION}

This is the first study to describe, in the same fetus, acute and chronic pathophysiological responses, peripheral inflammatory responses, and neural injury resulting from repeated exposure to LPS. This protocol resulted in hypoxemia and hypotension, elevated plasma IL-6 concentration, and brain injury in all fetuses. Injury was most prominent in the cerebral white matter and consisted of both diffuse damage and focal PVL, typical of white matter injury in preterm infants $(11,12,20,27)$. The extent of the injury ranged from $1 \%$ of the total cerebral white matter in the least affected fetus to $8.5 \%$ in the most affected fetus. We also observed a reduced cross-sectional area of the medullary corticospinal tract, a deficit that has been reported in $50 \%$ of cerebral palsy cases (33).

Fetal physiologic and inflammatory responses. The acute physiologic response to the first injection of LPS included fetal hypoxemia, acidemia, hyperlactemia, and hypotension. All of these responses were attenuated after subsequent LPS treatments, but fetuses remained mildly hypoxemic at the conclusion of the 5-d protocol. Attenuation of responses to repeated LPS exposure has been described previously $(34,35)$, and may be due to down-regulation of the LPS receptor CD14 (36). The fetal hypoxemia and metabolic acidosis after LPS are likely due to placental dysfunction as LPS, albeit at higher doses, increases umbilico-placental vascular resistance (37). It is also possible that placental exchange may have been restricted as a result of placental edema. The mild degree of chronic fetal hypoxemia during the 5-d treatment period could be due to a persistent impairment in placental gas transfer. The fetal hypotension may have resulted from impaired cardiac output, reduced peripheral vascular resistance, or a decline in fetal blood volume. A decrease in blood volume is suggested by the tendency for hematocrit and $\mathrm{Hb}$ concentration to increase after LPS (resulting from an increase in vascular permeability).

The normal response to hypoxemia in the fetus is an increase in cerebral blood flow, which serves to maintain cerebral $\mathrm{O}_{2}$ delivery $(22,38-40)$, although the ability to increase cerebral blood flow through vasodilatation is limited in the immature fetus (41). It has recently been shown that, during the fetal hypoxemia associated with LPS administration in the immature fetus, cerebral blood flow is not increased and cerebral delivery of $\mathrm{O}_{2}$ is impaired $(37,42)$; the observed fetal hypotension could have contributed to these changes. The absence of increased cerebral blood flow in response to LPS administration is consistent with our observation that there was no increase in the percentage of neuropil occupied by blood vessels in brains of LPS-exposed fetuses. Regression analysis showed that there was no relation between the extent of white matter injury and any of the physiologic parameters measured. Thus, we cannot determine which physiologic changes underlie the fetal brain injury.

It has been proposed that LPS induces peripheral myeloid cells to produce pro-inflammatory cytokines (24) via interac- 
tion with the CD14 receptor and Toll-like receptors (43) and activation of the transcription factor, nuclear factor (NF)- $\kappa \mathrm{B}$ $(44,45)$. We found that the concentration of IL- 6 in fetal plasma was significantly elevated $6 \mathrm{~h}$ after the first injection of LPS and to a lesser extent after the second injection. TNF- $\alpha$ was not elevated at $6 \mathrm{~h}$, but preliminary data from a companion study have shown that it is elevated several fold at $2 \mathrm{~h}$ after LPS administration (J. Duncan and P. Dalitz, unpublished observations). In the brain, pro-inflammatory cytokines increase the permeability of the blood-brain barrier via effects on endothelial cells and tight junctions (46), allowing the entry of macrophages into the brain parenchyma. This cascade may result in the activation of microglia and astrocytes and the up-regulation of pro-inflammatory cytokine production by these cells within the brain. It should be noted that there was no correlation between the maximal IL-6 level in the fetal plasma and the extent of white matter damage.

Brain injury. It is likely that the combination of high levels of circulating cytokines, the invasion of the brain by peripheral macrophages, and tissue hypoxemia all contribute to fetal brain injury. We have previously found that predominantly hypoxic insults in the fetus can cause white matter injury $(32,47)$, but the damage is neither as reproducible nor as severe as that resulting from LPS. Hence, the inflammatory cascade is likely to play a significant role in the development of brain injury in this paradigm. It is of interest that LPS can sensitize the immature brain to hypoxic-ischemic injury, although the mechanisms involved have not yet been unequivocally demonstrated (48).

In the present study, O4-positive preoligodendrocytes were the dominant stage of the oligodendrocyte lineage. This is in accord with the human, in which the peak period for the occurrence of PVL coincides with the time at which the O4 preoligodendrocyte cell predominates in the white matter (21). The basis for the particular vulnerability of pre- and immature oligodendrocytes to hypoxia/ischemia, oxidative stress, and free radical production $(49,50)$ is not yet understood; however, several factors are likely to be involved including a developmental lack of antioxidant enzymes (27).

Within PVL and less frequently within areas of diffuse injury, damaged axons not associated with dying neurons were observed, suggesting that axons had been specifically targeted. The cause of axonal damage is not precisely known, but it is possible that glutamate levels in the extracellular space increase in LPS-exposed animals either as a result of hypoxemia (51) or cytokine activation of microglia (52). Glutamate could activate receptors on oligodendrocytes or possibly on the myelin sheath itself causing a toxic influx of $\mathrm{Ca}^{2+}$. Excess $\mathrm{Ca}^{2+}$ will likely cause disruption to mitochondrial function and subsequent damage to the structural integrity of the axon (53). Oligodendrocytes express AMPA receptors as early as $63 \mathrm{~d}$ of gestation in fetal sheep (54) and it is known that activation of AMPA receptors is involved in mediating hypoxic-ischemic injury in oligodendrocytes in vitro (55) and in the developing rat brain (56).

In relation to cell types within the lesion, lectin-positive cells were concentrated in areas of damage. Currently there are no means of unequivocally determining whether these are acti- vated resident microglia or infiltrating blood macrophages but their morphology suggests that both phenotypes are present. Astrogliosis was also evident within areas of damage but was not as prominent as the microglial/macrophage response. This might relate to the time $(11 \mathrm{~d})$ that had elapsed between the initial exposure to LPS and examination of the tissue. Astrocytic proliferation occurs early in the evolution of PVL whereas microglial proliferation occurs several days later (20).

Neuropathology was observed in the medullary corticospinal tract and in the white matter of the spinal cord where we identified dying oligodendrocytes. The reduction in corticospinal tract cross-sectional area might indicate degeneration of corticospinal fibers or alternatively a failure of axonal growth. Such disruptions to the tract, which have also been reported in cerebral palsy (33), could result in impaired cortical control of voluntary muscles and may have important implications for the manifestation of neurologic disabilities postnatally. In our ovine model, it will be of interest to establish whether motor dysfunction occurs after birth following LPS exposure.

Acknowledgments. The authors thank Ms. Mehrnoush Lotfi-Miri, Mr. Alex Satragno, and Mr. Philip Moss for technical assistance, Associate Professor Greg Rice for assistance with cytokine assays, and the Center for Animal Biotechnology for their kind donation of the CD45 antibody.

\section{REFERENCES}

1. Gilles FH, Leviton A, Kerr CS 1976 Endotoxin leucoencephalopathy in the telencephalon of the newborn kitten. J Neurol Sci 27:183-191

2. Dammann O, Leviton A 1997 Does prepregnancy bacterial vaginosis increase a mother's risk of having a preterm infant with cerebral palsy? Dev Med Child Neurol 39:836-840

3. Dammann O, Leviton A 1997 Maternal intrauterine infection, cytokines, and brain damage in the preterm newborn. Pediatr Res 42:1-8

4. Dammann O, Leviton A 1998 Infection remote from the brain, neonatal white matter damage, and cerebral palsy in the preterm infant. Semin Pediatr Neurol 5:190-201

5. Bejar R, Wozniak P, Allard M, Benirschke K, Vaucher Y, Coen R, Berry C, Schragg P, Villegas I, Resnik R 1988 Antenatal origin of neurologic damage in newborn infants. I. Preterm infants. Am J Obstet Gynecol 159:357-363

6. Yoon BH, Romero R, Kim CJ, Jun JK, Gomez R, Choi JH, Syn HC 1995 Amniotic fluid interleukin-6: a sensitive test for antenatal diagnosis of acute inflammatory lesions of preterm placenta and prediction of perinatal morbidity. Am J Obstet Gynecol 172:960-970

7. Yoon BH, Romero R, Yang SH, Jun JK, Kim IO, Choi JH, Syn HC 1996 Interleukin-6 concentrations in umbilical cord plasma are elevated in neonates with white matter lesions associated with periventricular leukomalacia. Am J Obstet Gynecol 174:1433-1440

8. Deguchi K, Mizuguchi M, Takashima S 1996 Immunohistochemical expression of tumor necrosis factor alpha in neonatal leukomalacia. Pediatr Neurol 14:13-16

9. Yoon BH, Romero R, Kim CJ, Koo JN, Choe G, Syn HC, Chi JG 1997 High expression of tumor necrosis factor-alpha and interleukin-6 in periventricular leukomalacia. Am J Obstet Gynecol 177:406-411

10. Nelson KB, Ellenberg JH 1986 Antecedents of cerebral palsy. Multivariate analysis of risk. N Engl J Med 315:81-86

11. Banker BQ, Larroche J-C 1962 Periventricular leukomalacia of infancy. Arch Neurol $7: 386-410$

12. Volpe JJ 1997 Brain injury in the premature infant: neuropathology, clinical aspects, and pathogenesis. Ment Retard Dev Disabil Res Rev 3:3-12

13. Gilles FH, Averill-DR J, Kerr CS 1977 Neonatal endotoxin encephalopathy. Ann Neurol 2:49-56

14. Ornoy A, Altshuler G 1976 Maternal endotoxemia, fetal anomalies, and central nervous system damage: a rat model of a human problem. Am J Obstet Gynecol 124:196-204

15. Cai Z, Pan ZL, Pang Y, Evans OB, Rhodes PG 2000 Cytokine induction in fetal rat brains and brain injury in neonatal rats after maternal lipopolysaccharide administration. Pediatr Res 47:64-72

16. Yoon BH, Kim CJ, Romero R, Jun JK, Park KH, Choi ST, Chi JG 1997 Experimentally induced intrauterine infection causes fetal brain white matter lesions in rabbits. Am J Obstet Gynecol 177:797-802

17. Debillon T, Gras-Leguen C, Verielle V, Winer N, Caillon J, Roze JC, Gressens P 2000 Intrauterine infection induces programmed cell death in rabbit periventricular white matter. Pediatr Res 47:736-742 
18. Back SA 2001 Recent advances in human perinatal white matter injury. Prog Brain Res 132:131-147

19. Kimpton WG, Washington EA, Cahill NP 1994 The development of the immune system in the fetus. In: Thorburn G, Harding R (eds) Textbook of Fetal Physiology. Oxford University Press, New York, pp 245-255

20. Kinney HC, Back SA 1998 Human oligodendroglial development: relationship to periventricular leukomalacia. Semin Pediatr Neurol 5:180-189

21. Back SA, Luo NL, Borenstein NS, Levine JM, Volpe JJ, Kinney HC 2001 Late oligodendrocyte progenitors coincide with the developmental window of vulnerability for human perinatal white matter injury. J Neurosci 21:1302-1312

22. McCrabb GJ, Harding R 1995 Cerebral blood flow is increased throughout $12 \mathrm{~h}$ of hypoxemia in the mid-gestation ovine fetus. Reprod Fertil Dev 7:463-467

23. Egan PJ, Rothel JS, Andrews AE, Seow HF, Wood PR, Nash AD 1994 Characterization of monoclonal antibodies to ovine tumor necrosis factor-alpha and development of a sensitive immunoassay. Vet Immunol Immunopathol 41:259-274

24. Rothel JS, Hurst L, Seow HF, Pepin M, Berthon P, Corner LA, Wood PR 1997 Analysis of ovine IL-1 beta production in vivo and in vitro by enzyme immunoassay and immunohistochemistry. Vet Immunol Immunopathol 57:267-278

25. McWaters P, Hurst L, Chaplin PJ, Collins RA, Wood PR, Scheerlinck JP 2000 Characterisation of monoclonal antibodies to ovine interleukin- 6 and the developmen of a sensitive capture ELISA. Vet Immunol Immunopathol 73:155-165

26. Auer RN, Olsson Y, Siesjo BK 1984 Hypoglycemic brain injury in the rat. Correlation of density of brain damage with the EEG isoelectric time: a quantitative study. Diabetes 33:1090-1098

27. Back SA, Volpe JJ 1997 Cellular and molecular pathogenesis of periventricular white matter injury. Ment Retard Dev Disabil Res Rev 3:96-107

28. Baron W, de Jonge JC, de Vries H, Hoekstra D 2000 Perturbation of myelination by activation of distinct signaling pathways: an in vitro study in a myelinating culture derived from fetal rat brain. J Neurosci Res 59:74-85

29. Porter BE, Tennekoon G 2000 Myelin and disorders that affect the formation and maintenance of this sheath. Ment Retard Dev Disabil Res Rev 6:47-58

30. Maddox JF, Mackay CR, Brandon MR 1985 The sheep analogue of leucocyte common antigen (LCA). Immunology 55:347-353

31. Nitsos I, Rees S 1990 The effects of intrauterine growth retardation on the development of neuroglia in fetal guinea pigs. An immunohistochemical and an ultrastructural study. Int J Dev Neurosci 8:233-244

32. Rees S, Stringer M, Just Y, Hooper SB, Harding R 1997 The vulnerability of the feta sheep brain to hypoxemia at mid-gestation. Dev Brain Res 103:103-118

33. Stewart RM 1942 Observations on the pathology of cerebral diplegia. Proc R Soc Med 36:25-32

34. Whyte RI, Warren HS, Greene E, Glennon ML, Robinson DR, Zapol WM 1989 Tolerance to low-dose endotoxin in awake sheep. J Appl Physiol 66:2546-2552

35. Takemura T, Makino S, Takao T, Asaba K, Suemaru S, Hashimoto K 1997 Hypothalamic-pituitary-adrenocortical responses to single vs. repeated endotoxin lipopolysaccharide administration in the rat. Brain Res 767:181-191

36. Mengozzi M, Fantuzzi G, Sironi M, Bianchi M, Fratelli M, Peri G, Bernasconi S, Ghezzi P 1993 Early down-regulation of TNF production by LPS tolerance in human monocytes: comparison with IL-1 beta, IL-6, and IL-8. Lymphokine Cytokine Res 12:231-236

37. Garnier Y, Coumans A, Berger R, Jensen A, Hasaart TH 2001 Endotoxemia severely affects circulation during normoxia and asphyxia in immature fetal sheep. J Soc Gynecol Investig 8:134-142
38. Ashwal S, Dale PS, Longo LD 1984 Regional cerebral blood flow: studies in the feta lamb during hypoxia, hypercapnia, acidosis, and hypotension. Pediatr Res 18:13091316

39. Szymonowicz W, Walker AM, Yu VY, Stewart ML, Cannata J, Cussen L 1990 Regional cerebral blood flow after hemorrhagic hypotension in the preterm, nearterm, and newborn lamb. Pediatr Res 28:361-366

40. Jensen A, Berger R 1991 Fetal circulatory responses to oxygen lack. J Dev Physiol 16:181-207

41. McCrabb GJ, Harding R 1996 Role of nitric oxide in the regulation of cerebral blood flow in the ovine foetus. Clin Exp Pharmacol Physiol 23:855-860

42. Dalitz PA, Cock M, Rees S, Harding R 2002 Cerebral blood flow and oxygen delivery following endotoxin exposure in the preterm ovine fetus. J Soc Gynecol Invest 9:A173

43. Kopp EB, Medzhitov R 1999 The Toll-receptor family and control of innate immunity. Curr Opin Immunol 11:13-18

44. Wright SD, Ramos RA, Tobias PS, Ulevitch RJ, Mathison JC 1990 CD14, a receptor for complexes of lipopolysaccharide (LPS) and LPS binding protein. Science 249:1431-1433

45. Ghosh S, Baltimore D 1990 Activation in vitro of NF-kappa B by phosphorylation of its inhibitor I kappa B. Nature 344:678-682

46. Yang GY, Gong C, Qin Z, Liu XH, Lorris Betz A 1999 Tumor necrosis factor alpha expression produces increased blood-brain barrier permeability following temporary focal cerebral ischemia in mice. Brain Res Mol Brain Res 69:135-143

47. Rees S, Breen S, Loeliger M, McCrabb G, Harding R 1999 Hypoxemia near mid-gestation has long-term effects on fetal brain development. J Neuropathol Exp Neurol 58:932-945

48. Eklind S, Mallard C, Leverin AL, Gilland E, Blomgren K, Mattsby-Baltzer I, Hagberg H 2001 Bacterial endotoxin sensitizes the immature brain to hypoxic-ischaemic injury. Eur J Neurosci 13:1101-1106

49. Back SA, Gan X, Li Y, Rosenberg PA, Volpe JJ 1998 Maturation-dependent vulnerability of oligodendrocytes to oxidative stress-induced death caused by glutathione depletion. J Neurosci 18:6241-6253

50. Fern R, Moller T 2000 Rapid ischemic cell death in immature oligodendrocytes: a fatal glutamate release feedback loop. J Neurosci 20:34-42

51. Choi DW, Rothman SM 1990 The role of glutamate neurotoxicity in hypoxicischemic neuronal death. Annu Rev Neurosci 13:171-182

52. Bezzi P, Domercq M, Brambilla L, Galli R, Schols D, De Clercq E, Vescovi A, Bagetta G, Kollias G, Meldolesi J, Volterra A 2001 CXCR4-activated astrocyte glutamate release via TNFalpha: amplification by microglia triggers neurotoxicity. Nat Neurosci 4:702-710

53. Stys PK, Waxman SG, Ransom BR $1991 \mathrm{Na}(+)-\mathrm{Ca} 2+$ exchanger mediates Ca2+ influx during anoxia in mammalian central nervous system white matter. Ann Neurol 30:375-380

54. Furuta A, Martin LJ 1999 Laminar segregation of the cortical plate during corticogenesis is accompanied by changes in glutamate receptor expression. J Neurobiol 39:67-80

55. Matute C, Alberdi E, Domercq M, Perez-Cerda F, Perez-Samartin A, Sanchez-Gomez MV 2001 The link between excitotoxic oligodendroglial death and demyelinating diseases. Trends Neurosci 24:224-230

56. Follett PL, Rosenberg PA, Volpe JJ, Jensen FE 2000 NBQX attenuates excitotoxic injury in developing white matter. J Neurosci 20:9235-9241 